\title{
Tuberculose Infantil: a importância do rastreio
}

Sílvia Ferreira Silva, ${ }^{*}$ Nélia Costa, ${ }^{*}$ Isabel Brito Lança, ${ }^{* *}$ Graça Seves, ${ }^{* *}$ Anicete Cavaco, ${ }^{* * *}$ Maurílio Gaspar****

\section{RESUMO}

Introdução: A Tuberculose (TB) é um problema major de saúde pública. Todos os anos surgem cerca de 9 milhões de novos casos e ocorrem perto de 2 milhões de mortes. O controlo da TB em crianças tem sido frequentemente descurado uma vez que estas não são, regra geral, bacilíferas e como tal muitas vezes não são contempladas na execução dos programas de controlo da doença.

Descrição do caso: Apresenta-se o caso clínico de uma criança de 2 anos de idade a quem foi feito o diagnóstico de Tuberculose Pulmonar Doença, na sequência do rastreio realizado aos conviventes de um tio-avô materno com diagnóstico recente de Tuberculose Pulmonar em fase bacilífera.

Comentário: O rastreio de TB na idade pediátrica assume elevada importância, uma vez que as crianças constituem possíveis reservatórios da doença no futuro, existindo ainda morbilidade e mortalidade associadas à TB na infância.

Palavras-chave: Tuberculose; Rastreio; Contágio.

\section{INTRODUÇÃO}

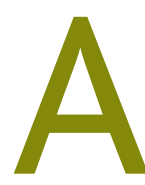

Tuberculose (TB) é uma infecção de transmissão aérea e um problema major de saúde pública. Todos os anos surgem cerca de $9 \mathrm{mi}-$ lhões de novos casos e ocorrem perto de 2 milhões de mortes. ${ }^{1}$ Embora todos os países sejam afectados, a maioria dos casos ocorre em África (30\%) e na Ásia (55\%). ${ }^{1,2}$

A incidência mundial da doença na infância é variável, compreendendo percentagens que variam entre os 3 e mais de $25 \%{ }^{3,4}$

Estes números levaram a Organização Mundial de Saúde a criar «The Global Plan to Stop TB 2006-2015» que tem como objectivos diminuir a incidência de TB até 2015, diminuir a prevalência e mortalidade para metade relativamente às taxas do ano de 1990 e detectar e tratar pelo menos $70 \%$ dos novos casos bacilíferos. ${ }^{1}$

Em Portugal, na última década do século XX, verificou-se uma diminuição progressiva da incidência de TB no grupo etário inferior a 15 anos, ${ }^{3,5}$ sendo que em 2001 registaram-se taxas nacionais de incidência de TB na or-

*Interna de Pediatria

**Assistente Hospitalar Graduada de Pediatria

***Chefe de Serviço e Directora do Serviço de Pediatria

**** Chefe de Serviço e Director do Departamento da Saúde da Mulher e da Criança ULSBA - Unidade Local de Saúde do Baixo Alentejo dem dos 8,3/100 000 na faixa etária 0-4 anos e de 5,6/100 000 na faixa etária dos 5-14 anos. ${ }^{3}$

A TB geralmente atinge as crianças através do contacto com doentes bacilíferos, sendo por isso considerada um excelente indicador sentinela, contribuindo para aferir o nível de TB na comunidade e a eficácia das medidas de controlo epidemiológico adoptadas. ${ }^{3} \mathrm{Na}$ infância o diagnóstico de infecção por Mycobacterium tuberculosis (Mt) é indicativo de uma transmissão recente, traduzindo uma falência do sistema de saúde pública. ${ }^{3}$

O controlo da TB em crianças tem sido frequentemente descurado uma vez que estas não são, regra geral, bacilíferas e por isso muitas vezes não são contempladas na execução dos programas de controlo da doença. ${ }^{2}$ No entanto, o rastreio na idade pediátrica assume elevada importância, uma vez que as crianças constituem possíveis reservatórios da doença no futuro, existindo ainda morbilidade e mortalidade associadas à TB na infância. ${ }^{2}$

A TB na idade pediátrica é um desafio diagnóstico porque apresenta características muito particulares no que respeita à grande variabilidade clínica (ou ausência da mesma) e por ter períodos de incubação variáveis. ${ }^{2,3}$ Outro aspecto, já referido anteriormente, relaciona-se com o facto das crianças com TB serem geralmente paucibacilares, havendo dificuldade na obtenção de amostras adequadas para bacteriologia. Assim, 
a confirmação do diagnóstico baseada na identificação do agente responsável nem sempre é possível., ${ }^{3,6}$

A sensibilização de todos os clínicos para a TB em idade pediátrica é fundamental, uma vez que esta é evitável e, na grande maioria dos casos, tem evolução favorável para a cura, com taxas de sucesso entre 95$100 \% .^{2}$

\section{DESCRIÇÃO DO CASO}

Os autores apresentam o caso clínico de uma criança do sexo feminino, de 2 anos de idade, natural e residente no distrito de Beja, que foi referenciada do Centro de Saúde para o Serviço de Urgência (SU) do Hospital de Beja com suspeita de Pneumonia.

Tratava-se de uma primeira e única filha de um casal saudável, não consanguíneo, com gestação vigiada, sem intercorrências, e com serologias do $3 .^{\circ}$ trimestre (HIV 1/2, VDRL, VHB) negativas. O parto foi de termo, no Hospital de Beja, distócico (cesariana por incompatibilidade feto-pélvica), verificando-se peso adequado à idade gestacional e choro imediato. Ao nascimento foi detectada sindactilia do $2 .^{\circ}$ e $3 .^{\circ}$ dedos dos pés (aguardava correcção cirúrgica). Tinha cumprido o Plano Nacional de Vacinação, sem vacinas extra-plano.

A família pertencia à Classe Social IV de Graffar, sendo os co-habitantes da criança os pais, avós e um tio maternos, todos com antecedentes irrelevantes. Referência a um tio-avô materno com diagnóstico recente de Tuberculose Pulmonar em fase contagiosa (bacilífero), com contacto diário com a família (não co-habitava mas faziam as principais refeições em conjunto). Apesar deste último familiar ter uma tosse persistente, a suspeita diagnóstica surgiu aquando da realização de uma radiografia de tórax pré-operatória que evidenciou alterações sugestivas de TB Pulmonar. No estudo subsequente realizou colheita de expectoração para exame directo e cultural. A identificação do $M t$ foi obtida no exame directo com a técnica de Ziehl-Neelsen, tendo iniciado terapêutica ainda a aguardar as culturas e teste de susceptibilidade.

Posteriormente realizou-se o rastreio aos seus contactos próximos, todos eles assintomáticos. Na sequência deste rastreio, foi efectuada à criança apresentada uma Prova de Mantoux e uma radiografia de tórax, que mostrou uma condensação no lobo médio à direita, sem imagem de adenopatias mediastínicas

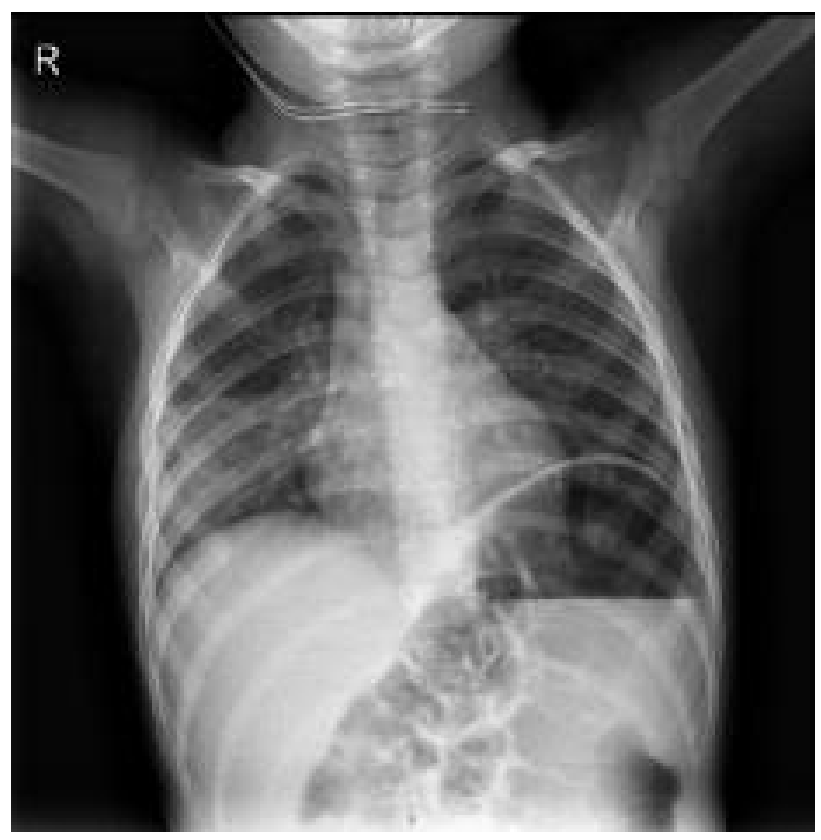

Figura 1. Radiografia de Tórax.

(Figura 1). Perante a evidência radiológica de pneumonia lobar, na ausência de clínica sugestiva (apirética, sem sintomatologia das vias respiratórias inferiores) mas com diagnóstico recente de otite média aguda bilateral medicada há $48 \mathrm{~h}$ com cefixima $(8 \mathrm{mg} / \mathrm{kg} 2$ id), é enviada ao Hospital de Beja para esclarecimento.

Na admissão apresentava um bom estado de nutrição e hidratação, apirexia, sem sinais de dificuldade respiratória, boa saturação de oxigénio transcutânea em ar ambiente, com rinorreia anterior mucosa escassa, hiperémia da orofaringe e hiperémia timpânica bilateral. A auscultação pulmonar era assimétrica, com ligeira diminuição do murmúrio vesicular no hemitórax direito, e com fervores crepitantes ipsilaterais. Não apresentava adenopatias palpáveis e o restante exame objectivo não tinha alterações.

Analiticamente, hemoglobina 12,9 g/dL, leucócitos $11,94 \times 10^{* 9} / \mathrm{L}$, com $28,5 \%$ de neutrófilos e $64,1 \%$ de linfócitos, função hepática e renal sem alterações e Proteína C Reactiva 4,7 mg/dL. Foi também realizada hemocultura que ficou em curso.

Foram colocadas como hipóteses de diagnóstico Tuberculose Pulmonar e/ ou Pneumonia Adquirida na Comunidade (PAC) e decidiu-se pelo seu internamento para esclarecimento. Iniciou antibioterapia com ampi- 
cilina ( $150 \mathrm{mg} / \mathrm{kg} / \mathrm{dia})$, via endovenosa, para cobertura dos agentes mais frequentemente implicados na PAC e realizou colheita de conteúdo gástrico, em 3 dias consecutivos, para pesquisa do $M t$. O exame directo foi negativo, ficando a cultura e teste de susceptibilidade aos antibacilares em curso. A Prova de Mantoux foi positiva, com induração de $14 \mathrm{~mm}$ às $72 \mathrm{~h}$.

Perante a história de contacto com doente bacilífero, positividade da Prova de Mantoux e radiografia de tórax com imagem de condensação, foi feito o diagnóstico provável de TB Pulmonar Doença, ${ }^{2,6}$ pelo que suspendeu ampicilina e iniciou terapêutica com isoniazida (INH) $15 \mathrm{mg} / \mathrm{kg} /$ dia, rifampicina (RMP) $15 \mathrm{mg} / \mathrm{kg} /$ dia e pirazinamida (PZA) $20 \mathrm{mg} / \mathrm{kg} / \mathrm{dia}$, esquema de 2 meses, mantendo a INH e RMP por mais 4 meses, nas mesmas doses. ${ }^{6}$ A cultura do aspirado do conteúdo gástrico e a hemocultura foram posteriormente negativas.

Aos restantes contactos (todos eles assintomáticos) foi também realizado rastreio com Prova de Mantoux e radiografia de tórax. Os pais, avô e tio maternos da criança tiveram Prova de Mantoux positiva, todos eles sem alterações nas radiografias de tórax, pelo que realizaram Interferon-Gamma Release Assays (IGRA) e pesquisa de bacilo de Koch nas secreções brônquicas. A pesquisa de $M t$ foi negativa no exame directo e cultural mas o IGRA foi positivo em todos, pelo que iniciaram terapêutica para TB Infecção/Latente. A avó materna teve rastreio negativo ficando com vigilância periódica.

Posteriormente a cultura do caso índice veio positiva para $M t$ multissensível (sensibilidade confirmada para INH, RMP, PZA, etambutol e estreptomicina).

\section{COMENTÁRIO}

Este caso mostra a importância da prevenção secundária (rastreio) em conviventes ou contactos próximos de doentes diagnosticados com TB, em especial se bacilíferos, tendo sido identificados vários casos passíveis de tratamento antes de desenvolverem doença.

A TB mantém-se como um problema de saúde pública a nível mundial, atingindo todas as faixas etárias. O diagnóstico precoce e isolamento são essenciais para evitar epidemias (ou mesmo pandemias). ${ }^{5}$ Apesar do número de casos ter vindo a diminuir nas últimas décadas, Portugal mantém uma das taxas mais elevadas de TB da União Europeia. ${ }^{5}$ Na tuberculose infantil, a forma mais comum é a pulmonar e, das formas extra- pulmonares, são mais frequentes a linfoadenopatia tuberculosa e a meningite tuberculosa. ${ }^{2}$

Em Pediatria a prática mais frequente é a suspeita diagnóstica, uma vez que as lesões são geralmente paucibacilares, o que condiciona grande dificuldade na obtenção de amostras adequadas para bacteriologia. ${ }^{6}$ Por isso, o diagnóstico baseia-se fundamentalmente no contacto com o doente bacilífero, na presença de clínica sugestiva, na positividade da prova tuberculínica e na identificação do $M t t^{6}$ Assim, o diagnóstico de tuberculose será suspeito se houve contacto de risco com doente com tuberculose activa, associado a alterações do estado geral, emagrecimento ou tosse persistente, pneumonia persistente/recorrente, sem resposta ao tratamento antibiótico ou presença de adenomegalias indolores. ${ }^{6}$ Será provável se Prova de Mantoux positiva, radiografia sugestiva, histologia sugestiva e/ou resposta favorável ao tratamento antituberculoso. E confirmado se identificação do $M t .^{6}$ Exames complementares de diagnóstico invasivos, como a broncofibroscopia, não têm geralmente interesse no diagnóstico de TB em crianças pequenas, pelo facto das lesões serem paucibacilares.

No caso apresentado, o diagnóstico de TB Doença foi provável, uma vez que havia contacto de risco, Prova de Mantoux positiva e alterações radiológicas sugestivas. ${ }^{2,6,7}$

A utilização do IGRA pode ajudar a distinguir TB infecção (Mantoux+ e IGRA+) de reacção cruzada (Mantoux+ e IGRA-), , ${ }^{2,8,9}$ associando a elevada sensibilidade da Prova de Mantoux com a maior especificidade do IGRA, ${ }^{8}$ sendo que nenhum dos dois testes consegue distinguir entre TB Infecção/Latente e TB Doença. ${ }^{10}$ Portanto, em Pediatria o IGRA não oferece vantagem substancial relativamente à Prova de Mantoux no que respeita à sensibilidade, no entanto pode ser importante na distinção de Prova de Mantoux falsamente positiva. ${ }^{9}$ Apesar da evidência ser ainda limitada, os estudos apontam para que o valor predictivo do IGRA seja semelhante ao da Prova de Mantoux. ${ }^{9}$ Outra das limitações deste teste é o resultado ser indeterminado, especialmente em crianças pequenas ou imunocomprometidas. ${ }^{9}$ De referir ainda que, segundo a American Academy of Pediatrics, a sensibilidade do teste IGRA em crianças abaixo dos dois anos de idade necessita de mais estudos prospectivos a longo prazo para avaliar da sua eficácia. ${ }^{10}$ 
No que respeita ao agente, o bacilo de Koch tem a particularidade de ter um crescimento muito lento em meio de cultura (6 a 8 semanas em meio de Lowenstein-Jensen e 2 a 3 semanas em meio líquido) e, sendo a tuberculose infantil paucibacilar, apenas 30 a $40 \%$ das crianças com TB pulmonar têm culturas positivas, o que explica que a cultura do conteúdo gástrico tenha sido negativa. No que se refere ao exame directo (com Ziehl-Neelsen), a positividade em amostras de crianças pequenas é inferior a $20 \%$, mesmo naquelas com diagnóstico provável de TB. ${ }^{9}$ Relativamente à colheita de material para exame directo/cultural, uma alternativa à aspiração de suco gástrico em 3 dias consecutivos é a indução da expectoração com nebulização de soro hipertónico (3\%-5\%), técnica que tem sido usada de modo seguro e eficaz em crianças pequenas. ${ }^{9} \mathrm{~A}$ cultura de uma única amostra de expectoração mostra resultados equivalentes a 3 colheitas de conteúdo gástrico. ${ }^{9}$

No caso descrito a criança era imunocompetente, com Prova de Mantoux positiva, tendo um bom estado geral de nutrição. No entanto, até $10-15 \%$ das crianças com diagnóstico confirmado de TB podem ter inicialmente Provas de Mantoux negativas. ${ }^{9}$ Factores relacionados com o hospedeiro, tais como idade (crianças pequenas), desnutrição, imunossupressão, outras infecções virais (sarampo, varicela, influenza), infecção recente ou TB disseminada podem diminuir a reactividade da Prova de Mantoux. ${ }^{9}$

No que respeita a outros exames complementares de diagnóstico, podem ter interesse particularmente em adolescentes, porque a doença com cavitação (rara em crianças mais jovens) tem sido observada nesta faixa etária. ${ }^{9}$ Nestes, a tomografia computorizada (TC) pode contribuir para o diagnóstico de TB pulmonar ao evidenciar alterações pulmonares na sua fase inicial, tais como a presença de cavitações ou linfadenopatia hilar intra-torácica. ${ }^{9}$ Nas formas de TB meníngea ou no caso de tuberculomas, a TC crânio-encefálica assume um papel importante no diagnóstico. ${ }^{9} \mathrm{O}$ uso da ressonância magnética tem particular interesse no caso da $\mathrm{TB}$ musculo-esquelética, particularmente quando envolve ossos e articulações. ${ }^{9}$

No caso clínico descrito, após o término do esquema terapêutico realizou-se uma radiografia de toráx de controlo que se mostrou completamente normal.

Devido à dificuldade na obtenção de amostras para bacteriologia, associada ao facto das crianças serem paucibacilares e terem uma apresentação clínica muito inespecífica, o diagnóstico torna-se um desafio para o clínico, sendo necessário um grande índice de suspeição para diagnosticar e consequentemente tratar a TB em idade pediátrica.

A TB tem vindo a atravessar séculos e avanços científico-médicos; no entanto, tratando adequadamente a TB em idade pediátrica pode-se contribuir para alterar, a longo prazo, o curso desta doença.

\section{CONFLITO DE INTERESSES}

Os autores declaram não possuir conflito de interesses.

\section{REFERÊNCIAS BIBLIOGRÁFICAS}

1. Stop TB Partnership. The Global Plan to Stop TB 2011-2015: transforming the fight towards elimination of tuberculosis. Geneva: World Health Organization; 2006.

2. Cruz AT, Starke JR. Pediatric tuberculosis. Pediatr Rev 2010 Jan; 31 (1): 13-26.

3. Leite AL, Carvalho I, Tavares E, Vilarinho A. Tuberculose doença: casuística de um serviço de pediatria no século XXI. Rev Port Pneumol 2009 Set-Out; 15 (5): 771-82.

4. World Health Organization. Guidance for national tuberculosis programmes on the management of tuberculosis in children. Geneva:WHO; 2006.

5. Antunes A. Programa Nacional de Luta contra a Tuberculose. Ponto de situação epidemiológica e de desempenho: Ano 2003. Programa Nacional de Controlo da Tuberculose. Sistema de Vigilância (SVIG -TB) 2003. Lisboa: Direcção-Geral da Saúde; 2004.

6. Pereira L, Marques L, Castro C, Vaz L. Diagnóstico e tratamento da tuberculose em pediatria - Recomendações das Secções de Pneumologia e Infecciologia Pediátrica da Sociedade Portuguesa de Pediatria. Rev Port Clin Geral 2003 Nov-Dez; 19 (6): 643-6.

7. Shingadia D. The diagnosis of tuberculosis. Pediatr Infect Dis J 2012 Mar; 31 (3): 302-5.

8. Antunes A, Villar M. Utilização dos testes de Interferão-Gama para o diagnóstico da tuberculose latente e activa, na prática clínica. Circular Informativa Nº: 6/23/02/2007. Lisboa: Direcção-Geral de Saúde; 2007.

9. Nicol MP, Davies MA, Wood K, Hatherill M, Workman L, Hawkridge A, et al. Comparison of T-SPOT.TB assay and tuberculin skin test for the evaluation of young children at high risk for tuberculosis in a community setting. Pediatrics 2009 Jan; 123 (1): 38-43.

10. Lighter J, Rigaud M, Eduardo R, Peng $\mathrm{CH}$, Pollack H. Latent tuberculosis diagnosis in children by using the QuantiFERON-TB Gold In-Tube Test. Pediatrics 2009 Jan; 123 (1): 30-7.

\section{ENDEREÇO PARA CORRESPONDÊNCIA}

Sílvia Ferreira Silva

E-mail: silviaraquelsilva@gmail.com

Recebido em 26/09/2012

Aceite para publicação em 10/03/2013 


\section{ABSTRACT}

\section{TUBERCULOSIS IN CHILDREN: THE IMPORTANCE OF SCREENING}

Introduction: Tuberculosis (TB) is a major problem in public health. Every year there are about 9 million new cases and around 2 million deaths worldwide. Control of TB in children is often been neglected, as children are considered less contagious than adults.

Case report: We report the case of an 2 year-old girl diagnosed with pulmonary tuberculosis following screening of contacts with a great-uncle who was diagnosed with pulmonary tuberculosis in the contagious phase.

Comment: In children, screening of TB is important because children can act as reservoirs of the disease, with subsequent morbidity and mortality from TB in childhood.

Keywords: Tuberculosis; Screening; Transmission. 